\title{
Cryptococcal Meningitis in Patient with Chronic Myeloid Leukemia
}

\section{Ricardo Parente Garcia Vieira1, Jucier Gonçalves Júnior², Acácio Vieira Machado Leite1, Viviane Chaves Pereira1, Nélio Barreto Vieira1, Modesto Leite Rolim-Neto1}

\author{
${ }^{1}$ School of Medicine, Universidade Federal do Cariri, Barbalha, Brazil \\ ${ }^{2}$ Medical Residency Program in Internal Medicine, Santa Casa de Misericórdia de Fortaleza, Fortaleza, Brazil \\ Email: *juciergjunior@hotmail.com
}

How to cite this paper: Vieira, R.P.G., Gonçalves Júnior, J., Leite, A.V.M., Pereira, V.C., Vieira, N.B. and Rolim-Neto, M.L. (2018) Cryptococcal Meningitis in Patient with Chronic Myeloid Leukemia. Health, 10, 1349-1356.

https://doi.org/10.4236/health.2018.1010104

Received: June 4, 2018

Accepted: October 19, 2018

Published: October 24, 2018

Copyright $\odot 2018$ by authors and Scientific Research Publishing Inc. This work is licensed under the Creative Commons Attribution International License (CC BY 4.0).

http://creativecommons.org/licenses/by/4.0/

\begin{abstract}
Objective: This study aimed to report the case of a female patient with chronic myeloid leukemia affected by cryptococcal meningitis. Case report: ML, white, 48 years old, female sex, previously diagnosed with chronic myeloid leukemia that has been refractive to the use of imatinib and who has recently begun using nilotinib, was admitted complaining of sudden and disabling migraine in the last 1 month associated with asthenia, adinamia, anorexia, disinterest for daily activities, dizziness, nausea, and vomiting. She evolved with ataxia, and started to stroll with help and showed decrease of muscular strength in her upper limbs. She also presented episodes of decrease of consciousness, with look fixation, no respond to sound stimulation, and short-term hearing loss. The cerebrospinal fluid showed presence of Cryptococcus sp. and, therefore, we began treatment with intravenous liposomal amphotericin B in the dose of $3 \mathrm{mg} / \mathrm{kg} /$ day, for 6 weeks. A new cerebrospinal fluid analysis, at the end of treatment, also showed rare structures that are compatible with Cryptococcus sp. As sequelae, she continued with hearing loss in her right ear and enhancement in her right auditory canal, seen in the magnetic resonance imaging. After stabilization and clinical improvement, she was discharged. After 3 weeks, she was hospitalized again with degeneration of the condition, and died due to intracranial hypertension secondary to cryptococcal infection. Final Considerations: This report reinforces the need of reflecting on fungi pathologies, especially in immunosuppressant patients, as well as the importance of early diagnosing and making a fast intervention, with the aims of providing quality of life and comfort to the patient and of minimizing neurological sequelae to the patient.
\end{abstract}

\section{Keywords}

Meningitis, Cryptococcal, Leukemia, Myelogenous, Chronic, Case Reports 


\section{Introduction}

Recently, cryptococcosis is one of the systemic infections with higher worldwide prevalence [1]. The risk factors related to cryptococcosis development are associated with low cellular immunity and are common in immunosuppressed individuals, such as patients with systemic erythematosus lupus, diabetes, kidney failure, transplanted and neoplasm bearers [2].

In Europe and in North America, the central nervous system infection through Cryptococcus neoformans affects up to $10 \%$ of the HIV seropositive population. Mortality in developed countries may even reach until 20\% [3]. In developing countries, infections in this site remain one of the main opportunistic infections and may reach $65 \%$ mortality rates, which correspond to 600 thousand deaths per year in immunosuppressed people [4].

Leukemias affect individuals in all ages. Until 2016, estimates showed 60,140 people diagnosed with the disease, which corresponds to $3.4 \%$ of all cancers [5]. In Brazil, estimates from the Department of Health show 5540 new cases of leukemia in men and 4530 in women. These values correspond to an estimated risk of 5.63 new cases for every 100 thousand men and 4.38 for every 100 thousand women [6].

Epidemiological data for chronic myeloid leukemia (CML) indicate that in every 100 thousand inhabitants, one or two will have the disease [7]. According to the National Cancer Institute, estimates showed that 8220 people were diagnosed with the disease and 1070 people died due to it in 2016 [8].

Therefore, it is not unusual that opportunistic diseases, such as central nervous system infections, are found in patients with leukemias. However, as far as we know, there is not a case report of cryptococcal meningitis in patients with CML.

We aimed to report the case of a patient with CML affected by cryptococcal meningitis.

\section{Case Report}

ML, white, 48 years old, female sex, previously diagnosed with CML that has been refractive to the use of imatinib and who has recently begun nilotinib, was admitted complaining of sudden and disabling migraine in the last one month that spread to the neck region and lasted for some minutes, which was relieved with dipyrone and tramadol, without ceasing. Her condition was associated with asthenia, anorexia, disinterest for daily activities, dizziness, nausea, and vomiting.

CML diagnosis was performed one year ago, when the patient came to her physician with complaints of weakness and diziness. At that moment, the physical exam demonstrated massive splenomegaly and paleness. Anemia, thrombocytosis and leucocytosis with shift to promyelocytes were present at the blood examination.

The patient evolved with ataxia, and started to stroll with help and with de- 
crease of muscular strength in the upper limbs. She also evolved with episodes of decrease of consciousness, with look fixation, no response to sound stimulation, and short-term hearing loss.

On the physical examination, she was pale, apathetic, disoriented with axial ataxia, generalized areflexia and hearing loss. Hospitalization was requested after laboratorial and imaging exams were performed. The cerebrospinal fluid analysis (Table 1 and Figure 1) showed the presence of Cryptococcus sp. and then treatment began with intravenous liposomal amphotericin B in the dose of 3 $\mathrm{mg} / \mathrm{kg} /$ day, for 6 weeks. The manometry was normal. In the end of treatment, a new cerebrospinal fluid analysis also showed rare structures that are compatible with Cryptococcus sp.

Patient evolved with improvement of her consciousness level, but with permanence of the condition of disorientation, anterograde amnesia, ataxia, migraine, continuous bilateral hearing loss that is more prominent to the right, and dizziness. The magnetic resonance showed periventricular enhancement that is compatible with a meningeal inflammatory process. After stabilization and clinical improvement, the patient was discharged using fluconazole, but she returned after 3 weeks with degeneration of her condition. She was hospitalized and deceased due to intracranial hypertension secondary to cryptococcal infection. Cranial CT scan was performed and intracranial hypertension was present. Neurosurgery evaluation revealed the need for external ventricular derivation. The surgery was performed but inspite that, in the next hours the conscience level decreased and orotraqueal intubation was needed. 24 hours after, the patient deceased because of refractory hypotension.

\section{Discussion}

Cryptococcosis is a mycosis caused by an encapsulated yeast, the Cryptococcussp, which currently presents two species: Cryptococcus neoformans (serotypes A and D) and Cryptococcus gattii (serotypes B and C) [9] [10]. The cryptococcal meningoencephalitis is diagnosed in around 1 million patients per year, causing more than 600 thousand deaths per year [11]. The most common age is between 30 and 50 years old [12]. However, it is an uncommon condition in immunocompetent patients [13]. Regarding sex, men present around $70 \%$ of the cases, whereas women, $30 \%$. This rate may be related to the influence of estrogens or to work exposures [14].

The scope of cryptococcosis by $C$. neoformans predominates when it is associated with conditions of low cellular imunity [15]. In our case, the CML must have been the primordial risk factor that lead to immunosuppression.

Cryptococcosis is a rare condition at childhood. Imunnocompettent individuals disease is mainly restricted to respiratory system while imunnocompromised patients commonly experiment hematogenical dissemination of the disease [12].

The initial clinical presentation of cryptococcosis with neurological symptoms, like in the present case, is not uncommon, because the fungus survives in 
Table 1. Laboratorial examinations requested during patient's admission.

\begin{tabular}{cc}
\hline \multicolumn{2}{c}{ Blood count } \\
\hline Red blood cells & $2.63 \mathrm{million} / \mathrm{mm}^{3}$ \\
Hemoglobin & $8.8 \mathrm{~g} / \mathrm{dL}$ \\
Hematocrit & $24.10 \%$ \\
Mean corpuscular volume & 91.63 \\
Mean corpuscular hemoglobin & 33.46 \\
Mean corpuscular hemoglobin concentration & 36.51 \\
RDW & $19.00 \%$
\end{tabular}

7500 (segmented: $33 \%$; eosinophils: $18 \%$; T lymphocytes: $15 \%$; monocytes $2 \%$. $32 \%$ are

Leukocytes large-sized cells, moderate nucleus/cytoplasm ratio, irregular nucleus, heterogeneous condensate chromatin)

Platelets

19,2000

\begin{tabular}{|c|c|}
\hline \multicolumn{2}{|c|}{ Clotting tests } \\
\hline Prothrombin time, seconds & 11.5 ; activity: $88.70 \%$ \\
\hline INR & 1.03 \\
\hline Time of partial thromboplastin, seconds & 25.30 seconds; ratio: 1.02 \\
\hline \multicolumn{2}{|c|}{ Electrolytes } \\
\hline Magnesium & $2.3 \mathrm{mg} / \mathrm{L}$ \\
\hline Serum calcium & $7.30 \mathrm{mg} / \mathrm{L}$ \\
\hline Sodium & $142 \mathrm{mg} / \mathrm{L}$ \\
\hline Potassium & $2.0 \mathrm{mg} / \mathrm{L}$ \\
\hline \multicolumn{2}{|c|}{ Kidney and liver function and hepatic necrosis enzymes } \\
\hline Urea & $8.1 \mathrm{mg} / \mathrm{dL}$ \\
\hline Creatinine & $0.4 \mathrm{mg} / \mathrm{dL}$ \\
\hline $\begin{array}{l}\text { Total bilirubin (direct bilirubin; } \\
\text { indirect bilirubin) }\end{array}$ & $0.39(0.19 ; 0.20)$ \\
\hline TGO & $10.0 \mathrm{U} / \mathrm{L}$ \\
\hline TGP & $33.0 \mathrm{U} / \mathrm{L}$ \\
\hline Alkaline phosphatase & $84.0 \mathrm{U} / \mathrm{L}$ \\
\hline Gama GT & $133.0 \mathrm{U} / \mathrm{L}$ \\
\hline \multicolumn{2}{|c|}{ Others } \\
\hline VHS & $90 \mathrm{~mm}$ \\
\hline Lactate dehydrogenase & 1108.0 \\
\hline Folic acid & $7.62 \mathrm{ng} / \mathrm{mL}$ \\
\hline Glucose & $85.0 \mathrm{~g} / \mathrm{dL}$ \\
\hline \multicolumn{2}{|c|}{ Serologies } \\
\hline HIV1 and 2 antibodies & Non-reagent \\
\hline Anti-HbCIgM & Non-reagent \\
\hline Anti-HbS & Non-reagent \\
\hline HbsAg & Non-reagent \\
\hline Anti-VHC & Non-reagent \\
\hline VDRL & Non-reagent \\
\hline
\end{tabular}

RDW: red cell distribution width; INR: International Normalized Ratio; TGO: serum glutamic oxaloacetic transaminase; TGP: serum glutamic-pyruvic transaminase; VHS: erythrocyte sedimentation rate; VHC: hepatitis $\mathrm{C}$ virus. 


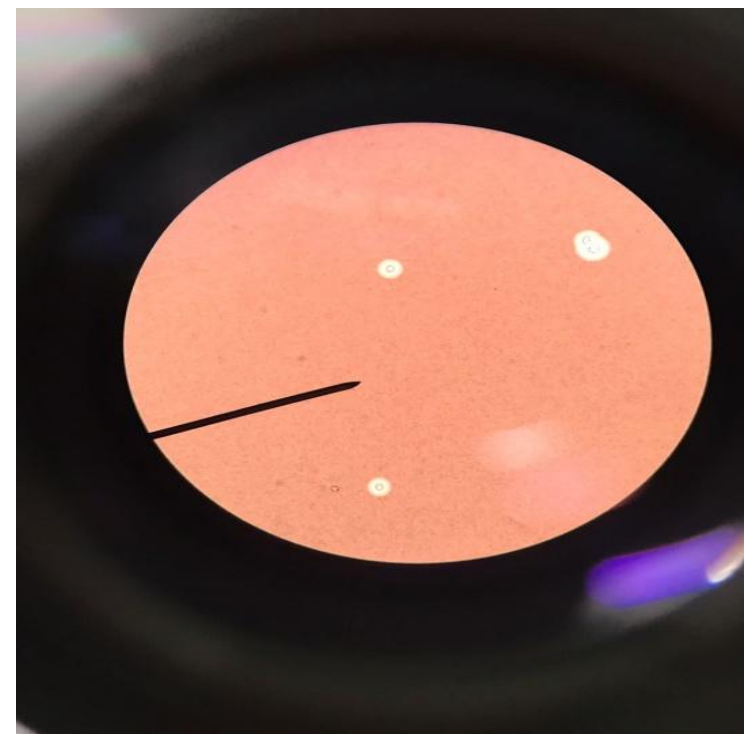

Figure 1. Microscopic analysis of the cerebrospinal fluid showing Cryptococcos sp.

the environment in contaminated soil with excretes of birds, and may be contracted through the inhalation of spores or dehydrated yeasts [12]. It has tropism through the central nervous system that is probably due to: high concentration of assimilable nutrients, lack of activity of the complement system, and weak or absent inflammatory response in the brain tissue. The brain is abundant in catecholamines, which the fungus may use for melanin synthesis. In addition, strains of Cryptococcus may survive and multiply in environments with low oxygen tension and relative high carbon dioxide tension in $37^{\circ} \mathrm{C}$ temperatures, as observed in the brain tissue [16].

In the beginning of the condition, our patient had severe migraine, ataxia and generalized areflexia that suggested cerebellar involvement. Most of the cryptococcosis cases are diagnosed as meningoencephalitis of insidious character [17]. The patients were typically presenting fever and/or migraine of slow and gradual beginning, which became disabling. Thus, signs and symptoms of meningitis or acute meningoencephalitis may be absent [18].

In immunosuppressed patients, meningoencephalitis occurs acutely with predominance of the serotype A and a large variation of clinical signs, including absence of meningeal signs. The inflammation of fungi-induced meninges may interfere in the reabsorption of the cerebrospinal fluid, resulting in intracranial hypertension syndrome [9] — which also made our patient evolve to death.

Most of these data belong to patients with HIV immunosuppression, but not with CML-which until now has not been showed in literature. Subtle differences may occur due to the alteration of the baseline disease. Studies defend that unlike HIV-related cryptococcosis, whose clinical characteristics were properly described in previous papers [19] [20], the epidemiology and manifestations of cryptococcosis are not clear in noncommunicable diseases affecting the population [21]. 
The diagnosis of meningitis by Cryptococcus sp. should be confirmed through the identification of this fungus in the preparation of China's ink and/or positive culture in the analysis of the cerebrospinal fluid [22]. Virchow-Robin dilated spaces, pseudocysts (also known as "gelatinous pseudocysts" and "soap bubbles" that correspond to the spread of fungi in Virchow-Robin spaces, invading the surrounding parenchyma or in confluent Virchow-Robin spaces), intercerebral nodules in masses (also named nodular injuries, granulomas, cryptococome or fungi brain abscesses), and hydrocephaly are aspects that may be observed in brain computed tomography or encephalic magnetic resonance when the central nervous system is affected [23]. In this case diagnosis was confirmed by the presence of criptococcus on cerebrospinal fluid (picture 1).

Anti-fungi with activity against Cryptococcus include polyphenols (amphotericin $\mathrm{B}$ ), flucytosine, and azoles. Echinocandins do not demonstrate in vivo activity against cryptococcus. The therapy combined with deoxycholate amphotericin $\mathrm{B}$ (AmB-d) and flucytosine is recommended as the first-line treatment of induction for disseminated cryptococcoses and central nervous system disease [24]. The action mechanisms of these drugs are the rupture of the fungal cell membrane and the inhibition of the DNA synthesis and fungus proteins, respectively [22] [25].

Aggressive management of intracranial hypertension is the main factor to reduce morbimortality. Other poor prognosis factors are degree of immunocompromise, prolonged corticosteroid use, HIV coinfection, mental status, delay on diagnosis, degree of leucocytosis in cerebrospinal fluid, sepsis, hi levels of criptococcal antigen titer [13]. The induction phase aims to make negative or effectively reduce the fungal burden and the minimal period of treatment is 2 weeks. The consolidation phase comprises maintenance of the mycologic negativity and normalization of clinical and laboratorial parameters for at least 8 weeks [24] [26].

\section{Final Considerations}

The case provides an association that has not been mentioned in the specialized literature: CML and cryptococcal meningitis. It reinforces the need of reflecting on fungi pathologies, especially in immunosuppressant patients, as well as on the importance of early diagnosis and fast intervention, with the aim of providing the patient a quality of life and comfort and of minimizing neurological sequelae.

\section{Conflicts of Interest}

The authors declare no conflicts of interest regarding the publication of this paper.

\section{References}

[1] Pizzani, A.T. and Santos, M.O. (2017) Cryptococose in HIV-Positive Patients: Sys- 
tematic Review of Literature. Revista Saúde UniToledo, 1, 90-106.

[2] Almeida, R.L. and Machado, E.R. (2014) Cryptococcus spp. Empacientes com HIV/SIDA: Revisão da Literatura. Ensaios e Ciência: Biológicas, Agrária e da Saúde, 18, 55-63.

[3] Espie, E., Pinoges, L., Balkan, S., et al. (2010) Cryptococcal Meningitis in HIV-Infected Patients: A Longitudinal Study in Cambodia. Tropical Medicine \& International Health, 15, 1375-1381. https://doi.org/10.1111/j.1365-3156.2010.02622.x

[4] Wajanga, B.M., Kalluvya, S., Downs, J.A., et al. (2011) Universal Screening of Tanzanian HIV-Infected Adult Inpatients with the Serum Cryptococcal Antigen to Improve Diagnosis and Reduce Mortality: An Operational Study. Journal of the International AIDS Society, 14, 48. https://doi.org/10.1186/1758-2652-14-48

[5] Siegel, R.L., Miller, K.D. and Jenmal, A. (2016) Cancer Statistics 2016. CA: A Cancer Journal for Clinicians, 66, 7-30. https://doi.org/10.3322/caac.21332

[6] Brasil. Instituto Nacional do Câncer José Alencar Gomes da Silva (INCA). Estimativa 2016. Incidência de Câncer no Brasil. Síntese dos Resultados e Comentários. http://www.inca.gov.br/estimativa/2016/sintese-de-resultados-comentarios.asp

[7] Höglund, M., Sandin, F. and Simonsson, B. (2015) Epidemiology of Chronic Myeloid Leukaemia: An Update. Annals of Hematology, 94, 241-247. https://doi.org/10.1007/s00277-015-2314-2

[8] National Cancer Institute (2016) Cancer Stat Facts: Leukemia - Chronic Myeloid Leukemia (CML). http://seer.cancer.gov/statfacts/html/cmyl.html

[9] Mascarenhas-Batista, A.V., Souza, N.M. and Sacramento, E. (2013) Fatores prognósticos na meningite criptocócica em hospital de referência para doenças infecciosas. Revista Baiana de Saúde Pública, 37, 68-89.

[10] Hagen, F., Khayhan, K., Theelen, B., et al. (2015) Recognition of Seven Species in the Cryptococcus gattiil Cryptococcus neoformans Species Complex. Fungal Genetics and Biology, 78, 16-48. https://doi.org/10.1016/j.fgb.2015.02.009

[11] Park, B.J., Wannemuehler, K.A., Marston, B.J., et al. (2009) Estimation of the Current Global Burden of Cryptococcal Meningitis among Persons Living with HIV/AIDS. AIDS, 23, 525-530. https://doi.org/10.1097/QAD.0b013e328322ffac

[12] Silva, M.P. and Gagliani, L.H. (2014) Diagnóstico e prevalência da meningite criptocócica em pacientes portadores da Síndrome da Imunodeficiência Adquirida-SIDA. UNILUS Ensino e Pesquisa, 11, s.p.

[13] Ramos, E.S., Galvão, M.L., Takatani, M., et al. (2013) Cerebelite aguda por Cryptococcus em paciente imunocompetente: Relato de caso. Rev Bras Clin Med São Paulo, $11,372-374$.

[14] Mafra, M.O., Neves, R.N., Lima, D.S., et al. (2008) Criptococose Disseminadaem Lúpus Eritematoso Sistêmico Juvenil. Revista Brasileira de Reumatologia, 48, 373-378. https://doi.org/10.1590/S0482-50042008000600010

[15] Mezzari, A., Wliebbelling, A., Freitas, G., et al. (2013) Criptococoseem um Hospital Público de Porto Alegre: Dados epidemiológicos. JInfection Control, 2, 135-139.

[16] Backes, P., Santos, J.I., Borsatto, E.M., et al. (2016) Diagnóstico laboratorial de Cryptococcus sp. no líquor. UNILUS Ensino e Pesquisa, 48, 10-14.

[17] Saag, M.S., Graybill, R.J., Larsen, R.A., et al. (2000) Practice Guidelines for Management of Cryptococcal Disease. Clinical Infectious Diseases, 30, 710-718. https://doi.org/10.1086/313757

[18] Mitchell, T.G. and Perfect, J.R. (1995) Cryptococcosis in the Era of AIDS-100 
Years after the Discovery of Cryptococcus Neoformans. Clinical Microbiology Reviews, 8, 515-548.

[19] Jongwutiwes, U., Sungkanuparph, S. and Kiertiburanakul, S. (2008) Comparison of Clinical Features and Survival between Cryptococcosis in Human Immunodeficiency Virus (HIV)-Positive and HIV-Negative Patients. The Journal of Infectious Diseases, 61, 111-115.

[20] Maduro, A.P., Goncalves, L., Inacio, J., et al. (2015) HIV/AIDS-Associated Cryptococcosis in Portugal Spanning the Pre- to Post-HAART Era: A Retrospective Assessment at the Genotypic Level Based on URA5-RFLP. Current Microbiology, 71, 449-457. https://doi.org/10.1007/s00284-015-0873-z

[21] Li, Y., Fang, W., Jiang, W., et al. (2017) Cryptococcosis in Patients with Diabetes Mellitus II in Mainland China: 1993-2015. Mycoses, 60, 706-713.

https://doi.org/10.1111/myc. 12645

[22] Cavalcante, E.G., Montoni, J.D., Oliveira, G.T., et al. (2014) Meningite criptocócica fatal em paciente com lúpus eritematoso sistêmico juvenil. Revista Brasileira de Reumatologia, 54, 155-158. https://doi.org/10.1016/j.rbr.2014.03.012

[23] Alvarenga, M.A., Vargas, A.A., Lima, M.S., et al. (2015) Abordagem cirúrgica de lesão granulomatosa criptocócica cerebral (criptococoma) em paciente imunocompetente. Arquivos Brasileiros de Neurocirurgia, 34, 73-78.

[24] Kung, H.C., Huang, P.Y., Chen, W.T., Ko, B.S., et al. (2017) 2016 Guidelines for the Use of Antifungal Agents in Patients with Invasive Fungal Diseases in Taiwan. Journal of Microbiology, Immunology and Infection, 51, 1-17.

[25] Sloan, D.J. and Parris, V. (2014) Cryptococcal Meningitis: Epidemiology and Therapeutic Options. Clinical Epidemiology, 6, 169-182. https://doi.org/10.2147/CLEP.S38850

[26] Kon, A.S., et al. (2008) Consenso em criptococose. Revista da Sociedade Brasileira de Medicina Tropical, 41, 524-544. 